\title{
LA FILIACIÓN EN LAS TÉCNICAS DE REPRODUCCIÓN HUMANA ASISTIDA*
}

\author{
Hernán Corral Talciani \\ Profesor de Derecho Civil \\ Universidad de los Andes
}

“¿Y 'padre'? - preguntó el DIC.

Se produjo un silencio incómodo. Algunos muchachos se sonrojaron [...] Uno de ellos, al fin, logró reunir valor suficiente para levantar la mano.

- Los seres humanos antes era - vaciló; la sangre se le subió a las mejillas-. Bueno, eran vivíparos

[...] En suma - resumió el director. Los padres eran el padre y la madre [...] Estos hechos son desagradables lo sé. Pero la mayoría de los hechos históricos son desagradables" (Aldous Huxley, Brave New World, Cap. I)

\section{Tecnoreproducción y efecto disociativo}

Louise Brown, la niña británica que fuera bautizada por la prensa como la primera "bebé probeta", por haber sido el primer ser humano concebido mediante una técnica de fecundación in vitro, ha cumplido ya 21 años. Fue justamente en 1978 cuando salió a la publicidad del mundo entero la posibilidad de recurrir a tratamientos reproductivos que sustituían la relación sexual entre los cónyuges como medio de darles descendencia.

Dos décadas después dichas técnicas se han expandido y reformulado en las más diversas modalidades, y han provocado serios desafíos tanto éticos como jurídicos. Sin embargo, no puede todavía considerarse pacífica la cuestión de la procedencia y admisibilidad de estos procedimientos ni la forma en que deben ser permitidos, regulados o acaso prohibidos por la ley civil.

La destrucción masiva de embriones, consecuencia necesaria de la legislación británica que establece el descarte de los embriones congelados pasados cinco años (art. 14.4 Human Fertilization and Embryology Act de 1990), causó en 1996 verdadera conmoción mundial.

Los avances en técnicas de clonación por vía de transplante núclear son hoy por hoy el más reciente reto a la conciencia de la humanidad sobre los criterios éticos obje-

"El texto es elaboración de una conferencia ofrecida por el autor en Buenos Aires para el Posgrado en Derecho de Familia de la Universidad Católica Argentina el 7 de septiembre de 1999. 
tivos y generalizables con los que pueden juzgarse la justicia o injusticia de los nuevos actos tecnoprocreativos.

Si hubiera que resumir en una palabra el efecto fundamental de este tipo de procedimientos de tecnología reproductiva, elegiría la palabra "disociación". Ellos partieron por disociar dos dimensiones que hasta su aparición estaban inseparablemente unidas: la unión sexual y la capacidad generativa. Justamente al contrario de la contracepción, en la reproducción médicamente asistida se busca el hijo como producto de una serie de procesos técnicos, que no contemplan la unión conyugal. Como decía Jérome Lejeune, es "hacer hijos, sin hacer el amor" 1 .

La connotación disociativa de la reproducción asistida no termina allí: separa también al niño recién concebido (llámesele como se quiera: zigoto, huevo fecundado, preembrión) del ámbito de protección natural que es el seno materno para transformarlo en un elemento o material de laboratorio. Parece comprensible en tales circunstancias que el valor de la dignidad humana de ese diminuto ser venga poco apreciada o reconocida, y que quede expuesta a los riesgos que implica el descarte por falta de "viabilidad" o calidad, el depósito en nitrógeno frío para abastecer nuevas experiencias, la experimentación o vivisección para utilizar sus células y tejidos.

En un tercer aspecto, la disociación alcanza también los lazos que unen a la criatura concebida con los partícipes del proceso de reproducción. Cuando se recurre a las llamadas "técnicas heterólogas", denominación con la que se conoce a aquellas que implican la utilización de gametos masculinos o femeninos de personas ajenas a aquellas que desean devenir en padres, se está disociando la paternidad o maternidad del hijo resultante. Más allá de lo que dispongan las leyes o los jueces, el niño ve desdoblada su calidad de hijo: social y legalmente puede ser hijo de alguien que no ha cooperado físicamente en su constitución como ser humano. La intervención de una madre gestante, introduce un elemento disociativo adicional, puesto que en este caso se separan dos elementos que son propios de la biología de la reproducción: la aportación genética y la aportación de gestación.

Es posible considerar, al menos hipotéticamente, que un niño puede llegar a tener hasta cinco eventuales padres. Así, el varón y la mujer que desean su venida al mundo, el titular del gameto masculino aportado y la mujer dueña del óvulo también aportado en el proceso, y finalmente la madre que gesta al niño. Dos posibles padres y tres posibles madres. $Y$ ello sin considerar que la madre gestante puede estar casada y presumirse la paternidad de su marido, lo que elevaría el número de posibles padres a seis: tres padres y tres madres.

Lo que comenzó siendo una aparente escisión meramente instrumental para lograr un fin terapéutico de superar la infertilidad, se revela ahora más bien como una nueva concepción de la imagen del hombre y de su forma de constituir la familia y las relaciones de paternidad o maternidad. La clonación en humanos, aunque después del

1 JÉROME, Lejeune, ¿Qué es el embrión humano?, Rialp, Madrid, 1993, p. 121. 
episodio de la oveja Dolly universalmente reprobado desde el Vaticano a la Casa Blanca pasando por el Consejo de Europa, ya no se presenta en círculos científicos como una desviación que debe ser prohibida, sino que como un medio de tratamiento de enfermedades en adultos. La producción de tejidos que no sean rechazados por el receptor, ha llevado a señalar que un método ideal sería elaborar un blastómero, a partir de un óvulo donado al que se le introduce el núcleo genético de una célula adulta del paciente. Aplicando la técnica de reprogramación del núcleo y obtenida células totipotenciales del blastómero, ellas podrían diferenciarse hasta producir los tejidos o los órganos que se necesitan ${ }^{2}$. Alguien podrá sostener, que los resultados terapéuticos se consiguen a costa de sacrificar un ser humano embrionario, pero la lógica de la disociación que, como creo haber expuesto preside la medicina de la reproducción asistida, no ve en ello sino un hito más de su camino.

Todo parte cuando se mira como éticamente aceptable separar el contacto sexual y la apertura a la recepción de un hijo como persona. Estamos llegando ya a la admisión de la producción utilitarista de un ser humano que difícilmente podrá llamar padre o madre a su clon predecesor.

Es pues el elemento disociativo aplicado a las relaciones entre generante y generado el que obliga al jurista a reflexionar y analizar la forma en que el Derecho, entendido no como una mera técnica de organización social, sino como arte de lo justo y de lo bueno, debe solucionar los problemas de filiación.

No parece existir este problema, aunque sí otros, cuando las técnicas de reproducción humana asistida se realizan con material genético de la pareja que desea el hijo, y sin intervención de terceras personas aportantes de gametos o de servicios de gestación.

\section{Biologicismo vs. voluntarismo: ¿Qué es ser padre o madre?}

Filiación es una palabra con la cual designamos la relación entre padre o madre y sus hijos, sin darnos cuenta que al hablar de madre, madre e hijo estamos dando por supuesto el concepto de filiación. Incurrimos en tautología.

Me parece que nadie duda que la filiación no es primariamente una relación jurídica, sino una relación natural, en el sentido de que antecede a la ley. Al mismo tiempo, esa relación es recogida por el Derecho por razones de orden familiar y social y le son atribuidos diversos efectos, derechos, obligaciones y responsabilidades.

Esta dicotomía entre "filiación natural" y "filiación legal" ha enturbiado la conceptualización de la filiación desde el punto de vista jurídico desde hace largo tiempo.

2 Cfr. SOLTER, Davor y GEARHART, John, "Putting Stem Cells to Work", en Science vol, 283, № 5407, 5 de marzo de 1999, pp. 1468-1470, y también TROUNSON, A. Y PERA, M., "Potential benefits of cells cloning for human medicine", en Reproduction, Fertility and Development, vol. 10, 1998, pp. 121-125. 
Es así como en la década de los años setenta tiene lugar un fuerte movimiento crítico sobre la forma en que los Códigos decimonónicos efectúan la recepción jurídica de la filiación. Se impugna la preferencia que se otorga a la filiación legítima, pero por sobre todo que la filiación tenga un contenido meramente formal y dependiente de la voluntad condescendiente del progenitor. Se tacha de injusta la previsión de que sólo el marido, mientras viva, pueda impugnar la paternidad del hijo adulterino, pudiendo con su voluntad mantener una paternidad falsa. Se critica también que la investigación de la paternidad esté fuertemente restringida, y que la ley favorezca el reconocimiento, ya sea expreso o tácito (por medio de la posesión notoria) como modo de determinación de la filiación ilegítima.

La reforma del Derecho de la filiación que comienza en Europa a fines de los años sesenta, y que se ha extendido casi universalmente, privilegia como uno de sus principios medulares el de la veracidad biológica. Es decir, el lazo sanguíneo constituye y revela la filiación, y esta realidad debe ser recogida por el Derecho, aun por sobre otros intereses (como la paz familiar, la estabilidad de los matrimonios, etc.).

El llamado "progresismo" jurídico de la época que enarbolaba las banderas de la biología se encontró a poco andar en una situación bastante incómoda. La aparición de las técnicas de reproducción humana asistida con intervención de terceros no parecían fácilmente armonizables con el principio de "verdad biológica", que debe llevar a la afirmación de paternidad o maternidad del aportante de gametos. Los otrora críticos del formalismo del régimen napoléonico comienzan a considerar que, al menos en ciertos casos, el elemento formal debería primar por sobre la verdad biológica, y que "padre legal" puede ser distinto de "progenitor biológico".

Notemos sin embargo que existe una gruesa incongruencia que no aparece resuelta: mientras para la procreación natural la filiación viene constituida por el elemento biológico de la descendencia sanguínea, en la reproducción médicamente asistida la filiación quiere construirse al margen de ese componente de realidad biológica. No parece un despropósito contraponer así la filiación natural a la filiación artificial o tecnológica que viene a ponerse en paralelo con la primera.

La interrogante sigue, por tanto en pie, ¿qué es ser padre, madre o hijo? ¿cómo debe recogerse jurídicamente esta calidad?

\section{Criterios para legislar o juzgar}

La experiencia del Derecho comparado, sea en aquellos ámbitos en los que el legislador ha intervenido como en aquellos en los que, a falta de ley expresa, ha tocado a los jueces resolver casos concretos relativos a problemas filiativos planteados por la tecnología reproductiva, muestra que no existe una uniformidad de criterios para enfrentar este delicado problema. 
De alguna manera, por regla general se trata de echar mano a diversos elementos para determinar la filiación, y para reconducirla a los supuestos tradicionales de la filiación sanguínea o por naturaleza.

Sólo en doctrina se ha planteado la posibilidad de diseñar una nueva forma de filiación, paralela tanto a la filiación por naturaleza como a la filiación adoptiva. Trabucchi tempranamente ha propuesto Ilamarla "filiación civil" ${ }^{3}$. La propuesta no ha gozado de fortuna, tal vez por la dificultad para caracterizar precisamente esa filiación, y determinar por qué se la llama de un modo tan ambiguo y genérico.

Pensamos que los diversos criterios que juegan para recomponer el lazo filiativo de un niño concebido tecnológicamente son básicamente seis: la aportación genética o titularidad de los gametos, la afectividad de los padres que desean al niño, el juicio previo de licitud o ilicitud de las técnicas, la analogía con la adopción, el interés superior del niño y la voluntad generativa o procrecional. Estos elementos a veces prefieren unos a otros, y en ocasiones se complementan para facilitar una solución más o menos razonable.

Una breve reseña de ellos y de su aplicación más frecuente nos ilustrará el complejo panorama existente.

\section{El elemento genético}

La aportación genética, es decir las personas a las que pertenecen las células germinales que dieron lugar al cigoto que luego deviene en un niño nacido, es el ele-mento tradicional que ha determinado la filiación desde los más remotos tiempos. Sólo que al no poder conocerse directamente esa titularidad, se la tenía por probada por el hecho del parto, respecto de la mujer, y, por regla general, por la presunción de paternidad del marido. En otros casos, la prueba de las relaciones sexuales con la madre podía probar esa aportación biológica.

En la actualidad, las pruebas del polimorfismo nuclear del A.D.N. permiten indicar con bastante mayor certeza la paternidad o maternidad biológica.

La filiación basada en la aportación genética no puede ser descartada sin más cuando se trata de niños traídos al mundo por técnicas reproductivas. En efecto, si se verifica una inseminación artificial o fecundación in vitro realizada con los gametos de la pareja que desea procrear, la paternidad y la maternidad se determinarán conforme a este criterio tradicional.

Por otra parte, incluso en técnicas con intervención de terceros, la aportación genética también juega un lugar importante. Así lo comprueban fallos de las Cortes norteamericanas que, resolviendo juicios de maternidad por subrogación, han determi-

3 TRABUCCHI, Alberto, "Procreazione artificiale e genetica umana nella prospettiva del giurista" en Procreazione artificiale e interventi nella genetica umana, Padova, 1987, pp. 15-16. 
nado la paternidad del varón comitente con cuyos espermios se fecundó al óvulo de la mujer portadora, y la maternidad de esta última, no sólo por el hecho de la gestación, sino por haber aportado también su material genético a la nueva criatura.

Un duro problema se observa cuando debe elegirse entre aportación genética (titularidad del óvulo) y aportación de nutrición y cuidado embrionario (titularidad de la gestación). No parece fácil decidir entonces cuál de las dos aportaciones, tan biológica la una como la otra, es la que debe primar.

\section{El elemento afectivo}

En muchos casos se invoca que la filiación en técnicas de reproducción humana asistida, más que fundarse en la fría biología, debe basarse en el calor de los afectos. Lo determinante para individualizar a los padres no es la titularidad de los gametos o la aportación biológica de gestación, sino la afectividad con la que el niño es acogido por la pareja receptora. La afectividad determina la paternidad y la maternidad.

Aunque sostenido en el plano doctrinario ${ }^{4}$, el elemento afectivo parece demasiado subjetivo e incierto para que propocione una ayuda suficiente cuando se trata de casos de conflicto. Porque si de afectos se trata ¿por qué se negaría la acción de contestación de la paternidad al marido que, si bien no fue capaz de negar el consentimiento para que su mujer fuera inseminada con semen ajeno, hoy rechaza por completo a una criatura que considera extraña y por la que no siente ningún cariño paterno?

Se observa, de este modo, que este criterio es más bien débil.

\section{La previa licitud e ilicitud de las técnicas}

La valoración que el ordenamiento haga sobre la legitimidad de estos procedimientos parece no tener importancia sobre la regulación de los lazos filiativos del niño resultante. Es verdad que, aunque se prohíba legalmente la llamada "donación" de gametos o el "alquiler" de úteros, si estos procedimientos se realizan contra esa prohibición y de ellos nace un niño, no es posible ignorarlo o considerarlo como uno de los efectos contractuales que la nulidad debe hacer desaparecer.

Pareciera entonces que debieran separarse ambos ámbitos: el de la valoración ético-jurídica de cada una de las modalidades de reproducción asistida, y la fijación de los vínculos parentales del niño nacido en virtud de ellas.

No estamos de acuerdo con este planteamiento, que, en el fondo, sólo se cumple cuando a priori concluimos que todas las técnicas deben ser procedentes y que el legislador o el juez no pueden declarar su ilicitud. La verdad es que difícilmente podrá desincentivarse legalmente una técnica si se regulan sus efectos filiativos como si ella fuera legítima e irreprochable. De allí que el precisar qué técnicas serán consideradas lícitas,

${ }^{4}$ Cfr. FIGUEROA, Gonzalo, Persona, pareja y familia, Edit. Jurídica de Chile, Santiago, 1995, pp. 115-116. 
cuáles moralmente rechazables si bien toleradas legalmente y cuáles derechamente prohibidas, es un juicio necesario para articular una regulación coherente y sistémica a los efectos filiativos.

Prueba de que este criterio no está del todo ausente, como podría hacer pensar la literatura jurídica existente sobre la materia, es la posición que en Europa se asume respecto de la maternidad por subrogación. Nadie duda que declarar que en los casos en los que, contra la prohibición legal, nazca un niño gestado por cuenta ajena la madre es la que lo ha dado a luz, es un elemento importante para desincentivar esta práctica.

\section{La analogía con la adopción}

Un criterio que parece estar presente para resolver los casos de conflicto entre aportantes genéticos, gestacionales y parejas receptoras, es la de aplicar analógicamente ciertas reglas que la legislación positiva establece para casos de adopción.

Es lo que sucede cuando se trata de la situación de embriones criopreservados en frío que se ofrecen a una pareja distinta de la progenitora.

También se invoca la adopción para otorgar primacía al varón o la mujer que desean al niño por sobre el titular del espermio o el huevo que le dieron la vida. Se dice, en el fondo, se estaría preadoptando a un niño, aún antes de que sea concebido.

A nuestro juicio, la analogía tiene sus limitaciones y no puede jugar un rol determinante, por cuanto la filiación adoptiva está pensada para proteger y amparar a un niño que, desgraciadamente, no cuenta con un hogar idóneo para acogerlo. El interés fundamental de la adopción es el niño huérfano o abandonado, y sólo secundariamente se valora el interés de los adoptantes a obtener descendencia. En cambio, en las técnicas con aportación de gametos es indudable que el punto de enfoque del interés se desplaza del hijo proyectado al de los adultos que desean un niño. Así como en la adopción se busca a unos padres para beneficiar a un niño que no los posee; en las técnicas heterólogas se crea un niño que nace huérfano para satisfacer las aspiraciones de los padres que desean acogerlo.

\section{El "best interest" del niño}

El standar jurídico consistente en el "interés superior del niño" (Convención de Derechos del Niño, art. 3) es también tomado en cuenta, aunque a veces sólo nominalmente y para apoyar decisiones justificadas en otros criterios. En los procesos norteamericanos es un elemento que se tiene especialmente en cuenta para decidir, a veces sobre la paternidad o maternidad, y en otras ocasiones sobre la custodia o cuidado personal del niño.

A nuestro entender este criterio debe también considerarse para elaborar el juicio previo de licitud e ilicitud de las técnicas, de manera que no deberían considerarse legítimos aquellos procedimientos que subordinan los intereses del niño por nacer a 
aquellos de los adultos que desean descendencia o de los equipos médicos de obtener un tratamiento terapéutico o desarrollar un proyecto de investigación.

\section{La llamada "voluntad procreacional"}

El criterio que goza de la mayor popularidad en los círculos que idealizan la medicina reproductiva como una nueva conquista de la razón y la libertad por sobre la naturaleza, es la llamada "voluntad procreacional" 5 , o lo que los estatutos y tribunales norteamericanos han denominado el "intent of reproduction" 6 .

Según este punto de vista la filiación debe cambiar de eje: de la aportación genética o biológica a la voluntad de procrear. Son padre y madre del hijo concebido por técnicas de reproducción humana asistida aquel varón y aquella mujer que con su expresión de voluntad determinaron que él fuera concebido, gestado y nacido.

Se justifica así que el varón que consiente en la inseminación de la mujer con semen ajeno sea identificado como el verdadero padre de la criatura, en la medida en que haya prestado su consentimiento a la técnica. También se funda la paternidad del nacido por fecundación postmortem en la expresión de voluntad del varón difunto.

El elemento volitivo plantea un tremendo desafío para el sistema tradicional, ya que éste concibe la filiación como algo independiente de la voluntad y que incluso puede producirse sin intención o contra la voluntad del padre o madre. Parece difícil señalar que en las técnicas de reproducción asistida debe primar la voluntad procreativa y que en la filiación natural ha de primar el lazo sanguíneo. De alguna manera, la propuesta de la voluntad procreacional tiende a superponerse a los criterios tradicionales para teñir con su color todo el entero sistema filiativo.

\section{Problemas y casos}

Reseñados los criterios a los que suele acudirse en busca de ayuda para fijar la filiación en las técnicas reproductivas, podemos resumir la forma en que se están resolviendo actualmente los principales problemas de filiación envueltos en estas prácticas.

\section{Filiación matrimonial: determinación e impugnación}

Uno de los primeros problemas que debieron ser abordados por legisladores y jueces fue si el marido que consiente en la inseminación o fecundación in vitro de su mujer con

5 En este sentido, por ejemplo RIVERO HERNÁNDEZ, Francisco, "La investigación de la mera relación biológica en la filiación derivada de fecundación artificial", en "l Congreso Mundial Vasco La filiación a finales del siglo XX, Madrid, 1988, pp. 143-144.

VETRI, Dominick, "Reproductive technologies and United States Law", en International and Compararive Law Quarterly vol. 37 (1988), pp. 505 y ss. 
espermios de un tercero, podía o no ejercer una acción de contestación de la paternidad, fundándose en que él no era el padre biológico de la criatura.

Tal vez sea ésta la situación que más intervención legislativa ha provocado hasta ahora en el Derecho occidental. Son muchos los ordenamientos que expresamente prohíben al varón que consiente el impugnar posteriormente su paternidad ${ }^{7}$. No se contempla generalmente el caso de donación de óvulos, para el que, con el mismo predicamento, podría sostenerse que la mujer que da a luz queda impedida para impugnar su propia maternidad invocando la aportación genética de una tercera donante de ovocitos.

La ley española 35/1988, de 22 de noviembre, provee para ambos casos: "Ni el marido ni la mujer, cuando hayan prestado su consentimiento, previa y expresamente, a determinada fecundación con contribución de donante o donantes, podrán impugnar la filiación matrimonial del hijo nacido como consecuencia de la fecundación" (art. 8.1). La ley británica de 1990 invierte los términos al disponer que el marido será considerado padre "a no ser que se pruebe que no dio su consentimiento a la inseminación o a la colocación del embrión esperma y óvulos, según el caso" (sec. 28.2). La ley francesa (ley no 94-653, de 29 de julio de 1994) aclara que la impugnación procede si se alega que el hijo no ha sido el fruto de la reproducción asistida o si el consentimiento carece de efectos (art. 311-20 del Código Civil). En este mismo sentido el Código Civil de Quebec (art. 539)

En ordenamientos en los que no existe norma sobre el particular, la aplicación de la regla clásica de la indisponibilidad del estado civil, y por tanto de la irrenunciabilidad de la acción lleva a los tribunales a acoger la acción del marido, a pesar de su inicial consentimiento. Es lo que sucedió hasta 1990 en Francia ${ }^{8}$ y ocurre actualmente en Alemania ${ }^{9}$. En Italia desde 1956 la jurisprudencia ha sido constante en admitir la acción

7 Cfr. VETRI, D., ob. cit., p. 509 contiene una referencia a la Uniforme Parentage Act y a los 29 estados que hasta 1988 habian ya legislado en este sentido en U.S.A. En Europa pueden mencionarse los Códigos Civiles de Bélgica (art. 318), Holanda (art. 201). Portugal (art. 1839), Suiza (art 256) y Grecia (art. 1471). En America Latina puede citarse el art. 187 del Código de Familia boliviano y art. 72 del Código de Familia de Costa Rica.

8 Trib. Nizza 30 de junio de 1976, Gazette Palais 1977, j. I, 48. Sin respaldo legal alguno, la Corte de París rechazó acoger la impugnación del varón sobre la base de su consentimiento (Trib. gr. inst. Bobigny, 18 de enero de 1990, D. 1990, 332), siendo criticada por la doctrina que señalaba que procedía la impugnación. Cfr. HAUSER, Jean Y HUET-WILLER, La Famille. Traité de Droit Civil sous la direction de Jacques Ghestin. LGDJ, t. X, $2^{2}$ edic., Paris, 1993, pp. 655-656.

9 BGH 12 de julio de 1995, Familienrecht, 1995, 1272. Cfr. ANDORNO, Roberto, "La procreación asistida en el Derecho comparado", en AA.VV., El derecho frente a la procreación artificial, Depalma, B. Aires, 1997, p. 105. 
de impugnación ${ }^{10}$, aunque la Corte de Casación en sentencia de 16 de marzo de 1999 enmienda este parecer negando esa acción al marido ${ }^{11}$.

La prohibición de impugnación no parece concitar unanimidad de pareceres. Así, el nuevo artículo 311-20 del Código Civil francés (introducido por la ley № 94-653, de 29 de julio de 1994) ha sido criticado por mantener una falsa paternidad aún contra la voluntad del marido que rechaza al hijo y privar a éste de la posibilidad de acogerse a la adopción plena ${ }^{12}$. Se plantea que es mejor permitir la impugnación, y que, en cambio, el marido consintiente sea considerado responsable de daños y perjuicios y condenado al pago de una pensión alimenticia en favor del hijo.

Es de observar, igualmente, que la exclusión legal de la acción de contestación se hace de un modo poco coherente, ya que para la filiación natural nada importa que el marido haya consentido en el adulterio de su mujer para que pueda posteriormente impugnar la presunción de paternidad. ¿Cuál es el motivo del diferente tratamiento?. ¿Por qué en un caso se deroga el principio de irrenunciabilidad de las acciones de estado $y$ en el otro se le mantiene, siendo que son supuestos fundamentalmente iguales: fecundación de la madre con semen de un tercero con acuerdo del marido?

\section{Paternidad no matrimonial del varón consentiente}

Cuando se trata de una pareja no casada y el varón consiente en que su compañera sea inseminada con semen propio o ajeno, surge el problema de cómo se determina la paternidad. En este caso no se puede aplicar la presunción de paternidad por faltar el vínculo matrimonial.

Se presenta entonces el problema de si el instrumento en que se manifiesta el consentimiento puede equipararse al reconocimiento de paternidad matrimonial. En principio, la respuesta que dan las leyes existentes es negativa, ya que no parece posible reconocer a un hijo que aún no existe por no haber sido concebido. Pero se considera que, fundándose en el consentimiento, es posible reclamar judicialmente el establecimiento de la paternidad. Así, la ley francesa señala que "se declarará judicialmente la paternidad fuera del matrimonio de quien, tras haber consentido la realización de una técnica de reproducción asistida, no reconoza al niño que sea fruto de la misma" (art. 311-20 del Código Civil).

10 Desde la sentencia del Tribunal de Roma de 30 de abril de 1956, Guistizia Civile 1956, I, 1612, la jurisprudencia de mérito se uniformó en esta posición. Cfr. CIRILLO, Francesco María, "La fecondazione artificiale eterologa de il rapporto di paternità nella filiazione legittima de in quella naturale" en Rivista di Diritto Civile, vol. 44 (1998), pp. 665-667.

C. Cas. 16 de marzo de 1999, en Giustizia Civile 1999, 1317, con nota favorable de C. Massimo Bianca. En dicha nota sin embargo reseña las fuertes críticas que ha merecido la sentencia por parte de $\mathrm{A}$. Finochchiaro, "La Cassazione non può svolgere una suplenza nelle funzioni riservate al legislatore", en Guida al diritto 1999. 54.

12

Cfr. RUBELLIN-DEVICHI, Jacqueline, en AA.VV., DROIT DE LA FAMILLE, Dalloz, 1996, n² 1325, p. 410 
En España se admite el procedimiento intermedio de determinación por expediente gubernativo aprobado por el juez encargado del Registro Civil, para el cual el documento que contiene el consentimiento se considera "escrito indubitable" (art. 8.2 de la ley 35/1988). No obstante, de acuerdo a este procedimiento, la oposición del pretendido padre frustra la determinación, obligando a los interesados a acudir al juicio de filiación.

Otra fórmula es la que establece el Código Civil de Québec, según el cual si el varón no casado no reconoce al hijo, no le queda a éste más que una acción de responsabilidad civil (art. 540). La fórmula es criticada por hacer resurgir las diferencias entre hijos nacidos en matrimonio o fuera de matrimonio ${ }^{13}$, aunque en verdad la diferencia deriva de la presunción pater is est más que de la aplicación de una técnica heteróloga.

Surge también el problema de si el varón que consiente y que reconoce al hijo no matrimonial, puede posteriormente impugnar ese reconocimiento basado en la falta de consanguinidad con el hijo por haberse utilizado semen ajeno. Las leyes suelen silenciar este supuesto, y se plantea la duda de si en tales casos debe aplicarse por analogía la exclusión de impugnación de la paternidad matrimonial (allí donde está establecida ${ }^{14} 0$ las reglas generales que favorecen la verdad biológica.

\section{3. "Donación" de embriones concebidos in vitro}

Aceptado que los embriones pueden ser criopreservados, es posible que la pareja con cuyos gametos fueron concebidos ya no desee utilizarlos, por ejemplo, porque ya ha obtenido descendencia. Se plantea entonces si los progenitores pueden entregar a otra pareja infértil dichos embriones. La ley española lo acepta. La ley francesa también pero de un modo excepcional, y calificándolo no de donación sino de acogimiento: "accueil' (cfr. art. L. 152-4 y 152.5 del Código de la Salud Pública), lo que induce a emparentar el proceso con una adopción ${ }^{15}$.

Aceptada la posibilidad es evidente que la paternidad es determinada por el consentimiento del varón, y la maternidad por la gestación de la mujer "donataria".

\section{Acciones del tercero aportante de gametos}

La sola aportación genética por medio de lo que se ha dado en llamar impropiamente "donación de gametos", en general, no es aceptada para acoger la reclamación

13 BEAULNE Jacques, "La médicine moderne de la procréation et son influence dans le droit des personnes et de la famille", en Revue Générale de Droit, vol. 26(2) 1995, pp. 256-257.

14 Es la opinión de RIVERO HERNÁNDEZ, Francisco, en LACRUZ BERDEJO, José Luis y otros, Elementos de Derecho Civil IV. Derecho de Familia, Bosch, $4^{a}$ edic., 1997, pp. 528-529, aunque exceptúa el caso en que el hijo haya nacido por hecho distinto de la fecundación artificial consentida por el varón. ciones que son, en su formulación, extremadamente análogas a aquellas previstas para la adopción de un niño. 
de paternidad o maternidad del hijo resultante de una técnica reproductiva. El supuesto no es considerado por la doctrina, ya que se presume que el "donante" no tiene interés alguno en reclamar para sí la filiación.

La ley francesa, no obstante, señala que no podrá establecerse "ningún vínculo de filiación entre el autor de la donación y el niño fruto de la donación" (art. 311-19 del Código Civil). En España, la ley 35/1988 dispone que, en los casos en los que deba revelarse la identidad del donante, esa revelación "no implica, en ningún caso, determinación legal de la filiación (art. 8.3).

Sin embargo, cuando se trata de maternidad por subrogación, la mujer que, además de gestar al hijo ha contribuido con sus gametos, puede querer reclamar su propia maternidad. Los tribunales norteamericanos la han reconocido como madre, no tanto por haber dado a luz la criatura, sino además por haber contribuido con su aportación genética ${ }^{16}$.

\section{Derechos del hijo frente al "donante de gametos"}

Una de las cuestiones más polémicas que ha suscitado la práctica de técnicas heterólogas es la armonización entre los derechos del hijo a conocer a sus padres y la reserva o anonimato que se quiere garantizar a quien aporta sus gametos sin el deseo de ser padre o madre.

La confrontación entre el derecho a la identidad del hijo y el derecho a la intimidad del progenitor biológico ha generado un intenso debate. Cuatro śon las posibles opciones para solucionar este enfrentamiento:

$1^{\circ}$ ) Garantizar el anonimato absoluto del donante: es la solución que parece primar en la legislación francesa (art. L. 673-7 C. santé publ). Incluso expresamente se excluye cualquier acción de responsabilidad en su contra (art. 311-19 del Código Civil).

$2^{\circ}$ ) Garantizar el anonimato general y relativo del donante: Es el caso de la ley española, para la cual "los hijos nacidos tienen derecho ... a obtener información general de los donantes que no incluya su identidad" y sólo por excepción cuando existan circunstancias extraordinarias que comporten un comprobado peligro para la vida del hijo o cuando proceda con arreglo a las leyes procesales penales, puede revelarse la identidad (art. 5.5 ley 35/1988). El Código Civil de Québec extiende este derecho a los descendientes del hijo (art. 542).

$\left.3^{\circ}\right)$ Otorgar derecho para conocer la identidad del donante pero sin atribuirle la paternidad: es la solución de la ley sueca (ley 1.140 de 20 de diciembre de 1984) que otorga tal derecho al hijo "una vez alcanzada la madurez suficiente" (art. 4). La legis-

\footnotetext{
16

Así en el famoso caso "Baby M", la Corte Suprema de New Jersey, junto con invalidar el contrato de maternidad subrogada, consideró que los padres de la criatura eran el varón comitente y la madre sustituta que había contribuido con su óvulo. Otorgó la custodia al padre, pero reguló derecho de visitas en favor de la madre gestante (New Jersey Super. 267.542 A.2d 52, 1988).
} 
lación austríaca (ley de $1^{\text {}}$ de julio de 1992) autoriza el ejercicio de ese derecho a partir de los catorce años.

$4^{\circ}$ ) Otorgar derecho no sólo para conocer la identidad sino para reclamar la paternidad del donante: es una fórmula que no tiene apoyo general, pero que se mantiene como posible cuando no sea factible atribuir la paternidad o marido de la mujer, por defecto de consentimiento u otra causa.

Pareciera que también debe darse esta solución cuando se trata de fecundación de mujer sola. La legislación española al haber legitimado esta práctica ha llevado a los autores a indicar que en tal caso el hijo sólo puede pretender determinar la maternidad y carecerá irremediablemente de padre ${ }^{17}$.

\section{La fecundación postmortem}

Cuando se pretende que el semen congelado dejado por el varón difunto sea empleado para inseminar a una mujer que ha sido su cónyuge o concubina, surge el problema de la filiación paterna del hijo así procreado.

Las leyes no llegan normalmente a considerar este supuesto. Algunas porque excluyen este tipo de procedimientos (así la ley sueca y la francesa). Otras, como la española, porque dan por descontada la filiación del hijo respecto del progenitor premuerto, cumpliéndose los requisitos que ella establece, entre otros, que exista consentimiento expreso y que se proceda dentro de los seis meses siguientes al fallecimiento (art. 9.1).

\section{La maternidad por subrogación}

La legislación europea se ha mostrado contraria a la práctica de la maternidad de sustitución o por encargo. Incluso en países que no tenían aún legislación sobre la materia, los tribunales habían declarado nulos por objeto ilícito los contratos de gestación por cuenta ajena y rechazado la aplicación de la normativa de la adopción plena para conseguir el propósito de esta práctica (así en Francia ${ }^{18}$ ). La ley española se pronuncia directamente sobre la nulidad del contrato, y regula la filiación: "la filiación de los hijos nacidos por gestación de sustitución será determinada por el parto" (art. 10.2). La ley británica afirma también que "la mujer que esté embarazada o lo haya estado como resultado de haberle sido implantado un embrión o esperma y óvulos, deberá ser considerada como la madre del niño a título exclusivo". (sec. 27.1).

En los casos norteamericanos las Cortes discrepan sobre la eficacia del surrogate parenting arrangement: En "Baby M" la Corte Suprema de New Jersey consideró inválido el acuerdo; lo contrario estimó la Suprema Corte de California en el caso Johnson

17 RIVERO HERNÁNDEZ, F. en Derecho de Familia ... cit., p. 529.

18 Corte de Casación 31 de mayo de 1991, R. Dalloz Sirey, 1991, 30, p. 417. Cfr. GOBERT, Michelle, "Réflexions sur les sources du droit et les 'principes' d'indisponibilité du corps humain et de l'état des personnes" en Revue Trimestrielle de Droit Civil, 1992 (3), pp. 489 y ss. 
v. Calvert ${ }^{19}$. La atribución de la maternidad varía según si la madre gestante es también la titular del óvulo, caso en el cual se la reconoce como la madre del niño (caso Baby M), o si la madre comitente es la titular del óvulo y no la gestante, caso en el cual se atribuye la maternidad a la mujer que deseaba ser madre (Johnson v. Calvert). En este último litigio la Corte Suprema de California rechazó algunas propuestas que sugerían otorgar a ambas mujeres (la comitente-genética y la gestante) el estado de madres del niño.

Finalmente, el hijo puede haber sido concebido con semen del marido y con óvulos de una donante, pero siendo la mujer que desea la maternidad la que gesta al embrión resultante. Producido el divorcio de la pareja el padre pide la custodia de las hijas (eran gemelas) en contra de su mujer, alegando que ésta no es la madre biológica. La Corte de Nueva York rechazó la demanda del marido y afirmó la maternidad de la madre gestante, considerando a la vez la voluntad de asumir la maternidad y el aporte biológico de la gestación ${ }^{20}$.

La incertidumbre producida en la materia lleva a la American Bar Association en su Guide to Family Law a recomendar que si alguien está pensando en contratar una maternidad subrogada debería buscar primero asistencia legal ${ }^{21}$.

\section{Analisis de reformas a la legislación chilena y argentina}

\section{El nuevo art. 182 del Código Civil Chileno}

El 27 de octubre de 1999, entró en vigencia que la ley № 19.585 que introduce una extensa reforma al Código Civil para establecer un nuevo estatuto de la filiación. La reforma sigue las aguas de la ley española de 1981 y de la ley argentina de 1985 . Se establece así una filiación por naturaleza que puede calificarse de matrimonial o no matrimonial para efectos de su determinación e impugnación, no obstante producir iguales efectos en materias alimenticias, de patria potestad y de derecho sucesorio.

El proyecto, presentado por el Ejecutivo en 1993, no consideraba el tratamiento de la filiación en las técnicas de reproducción asistida. Es más existía otro proyecto en trámite que pretendía regular tanto la admisibilidad de las técnicas como sus efectos filiativos.

Cuando el proyecto de filiación llegó al Senado, algunos senadores hicieron ver que la aplicación completa del principio de la libre investigación de la paternidad, por

19 CALVERT V., Johnson, No. X-633190 (Cal. App. Dep't Super. Ct. Otc. 22, 1990) slip.

20 McDonald v. McDonald, 608 N.Y.S. 2d 477 (1994).

21 The American Bar Association, Guide to Family Law, U.S.A., 1996, p. 34. Según la información que se proporciona, algunos pocos estados han excluido legalmente el contrato; otros lo restringen o podrían dar a la madre subrogada el derecho de conservar al niño después del nacimiento. 
medio de pruebas biológicas, podía perturbar la tranquilidad de las familias en las que se había ya insertado con éxito un niño concebido por medio de técnicas heterólogas.

Después de una discusión bastante intensa, y que incluso se dió por separado del resto del texto del proyecto, una mayoría de senadores se avino a dar su aprobación a un nuevo art. 182 del Código Civil, que reza como sigue:

"Es padre y madre del hijo concebido mediante técnicas de reproducción humana asistida el varón y la mujer que se someten a ellas.

No podrá impugnarse la filiación determinada de acuerdo con el inciso precedente, ni reclamarse otra distinta".

La norma nos parece de una redacción muy poco afortunada por lo imprecisa y poco rigurosa. Suscita innumerables dudas: ¿qué entiende el precepto por técnicas de reproducción humana asistida?; ¿qué alcance tiene la expresión "someterse a ellas"? ¿Implica consentimiento?, ¿De qué tipo?. ¿Cuál es el medio por el cual constará la filiación tecnológica que ella regula?, ¿Debe equipararse a la matrimonial y a la no matrimonial dependiendo del estado civil de la pareja receptora?

Para dar respuestas a estas múltiples interrogantes, no cabe sino acudir a la historia del establecimiento de la norma y al contexto general de la ley en la cual se encuentra inserta. Así podemos inferir que la norma no se aplica sino a las técnicas heterólogas (con donación de semen o de óvulos) en parejas heterosexuales, y que su único objeto es limitar la acción del varón o mujer consintiente para impugnar su paternidad o maternidad así como la acción de reclamación del progenitor biológico.

Subsiste la duda sobre el derecho del hijo a impugnar la paternidad o maternidad formal determinada por el art. 182, para reclamar la filiación respecto del donante de gametos. A nuestro juicio, la historia del precepto (del cual se eliminó un inciso tercero que disponía que la donación de gametos no importaba parentesco), el contexto general de la nueva normativa que establece como principio general que "la ley posibilita la investigación de la paternidad o maternidad" (art. 195 del Código Civil), así como los textos internacionales que abogan por el derecho del niño a conocer a sus padres en la medida de lo posible (Convención de Derechos del Niño, art. 7), llevan a la conclusión de que el hijo puede ejercer la acción de impugnación de la filiación tecnológica y reclamar la biológica.

\section{El proyecto de Código Civil argentino de 1998}

El Proyecto de Código Civil redactado por la Comisión designada por el Decreto 685 de 1995, y que fuera elevado al Ministro de Justicia con fecha 18 de diciembre de 1998, contiene dos normas que se refieren a nuestro tema: se trata del inciso cuarto del art. 543 y el inciso segundo del art. 563.

La primera norma se refiere a la determinación de la maternidad en casos de maternidad subrogada: "La maternidad del nacido corresponde a la mujer que lo ha ges- 
tado, aun cuando se demuestre que le fue implantado un óvulo fecundado de otra mujer, sea tal práctica lícita o ilícita" (art. 543.3).

La segunda disposición se refiere en cambio a la paternidad matrimonial en casos de fecundación asistida con semen de tercero: "No es admisible la impugnación de la paternidad si el marido consintió la fecundación artificial de la cónyuge o la implantación de un óvulo fecundado con gametos provenientes de un tercero, sea tal consentimiento lícito o ilícito" (art. 563.3).

Como vemos, el Proyecto parece inclinarse por el criterio más generalizado entre las legislaciones existentes: vedar la impugnación del marido consintiente de la presunción de paternidad y atribuir la maternidad legal a la madre gestante en caso de aportación genética o encargo de otra mujer.

Respecto de la prohibición de impugnación de la paternidad cabe hacer presente, sin embargo, que ella parece sólo alcanzar al marido que ha consentido en el uso de gametos ajenos. En cambio, la acción de impugnación de esa paternidad quedaría abierta para el hijo, de acuerdo con la norma del art. 565 que se refiere a ella sin hacer restricción alguna. De este modo, la exclusión de la impugnación sólo puede aplicarse tratándose del marido y sus herederos, que son los únicos a los que se refiere la norma del art. 563 donde se encuentra el inciso que se refiere a la fecundación asistida ${ }^{22}$.

Y si el hijo puede impugnar, ¿podrá reclamar la paternidad del aportante de semen? Por la generalidad de los términos del art. 557 la respuesta debiera ser afirmativa. Con mayor razón, ha de sostenerse esta conclusión si el marido impugna la paternidad probando que no consintió en el uso de material genético de un tercero.

Nada se dispone en Proyecto para los casos de aplicación de las técnicas entre concubinos. En tal caso, si el varón que consiente no reconoce al hijo una vez que éste haya nacido, difícilmente podrá atribuírsele la paternidad. Cuando más podría sostenerse que dicho concubino incurre en responsabilidad extracontractual. Se aplicaría por analogía lo dispuesto en el art. 551 del Proyecto en el sentido de que "los daños causados al hijo por no haberlo reconocido son indemnizables...".

La norma que se refiere a la maternidad cubre tanto los casos de donación de óvulos como de maternidad subrogada. En ambos casos un óvulo fecundado es transferido a una mujer para que lo geste, pero en el primer supuesto (donación de óvulos) la gestante es quien quiere ser madre del hijo por nacer, mientras que en el segundo (maternidad subrogada) la mujer que se embaraza lo ha hecho para entregar posteriormente el hijo a otra mujer, que puede ser o no la titular del óvulo. Para los dos casos, la norma es perentoria: la maternidad corresponde a la gestante.

De esta manera, se impide que pueda impugnarse la maternidad de gestación fundándose en que la aportación genética corresponde a otra mujer. No se aplicaría el

22 No parece caber la posibilidad de que el tercero donante impugne la paternidad matrimonial, ya que el Proyecto no da acción para impugnar la presunción de paternidad al tercero que se pretende progenitor del hijo. 
art. 562 que permite la impugnación de la maternidad al marido, sus herederos, al hijo, a los interesados, o incluso a la que aparece inscrita en el registro, "por no ser la mujer la madre del hijo que pasa por suyo". Como el art. 543 no es una regla meramente probatoria, sino que atributiva, en el caso de aportación de óvulo, la mujer gestante "es" la madre del hijo que pasa por suyo.

Parece en cualquier caso curioso que, tratándose de donación de semen no se niegue la acción de impugnación al hijo, como sí se lo hace respecto de la donación de óvulos. Tal vez la contribución que hace la gestante en el desarrollo del niño justifique en parte el diferente tratamiento.

Pero yendo más al fondo: pareciera que lo que determina las reglas de filiación es una implícita valoración de la admisibilidad de los diferentes procedimientos reproductivos. Los redactores del Proyecto han tenido el exquisito cuidado de señalar en ambas normas, que las consecuencias filiativas que disponen no prejuzgan sobre la juridicidad o antijuridicidad de las técnicas: "sea tal práctica lícita o ilícita" (art. 543); "sea tal consentimiento lícito o ilícito" (art. 563). Sin embargo, no puede dejar de constatarse que cuando se trata de técnica con donación de semen la ley aparece respaldando la voluntad de los usuarios de la técnica: atribuir la paternidad al marido a pesar de no ser el padre biológico. Por el contrario, cuando se trata de una maternidad de sustitución la ley aparece contraviniendo el contrato de gestación por cuenta ajena, atribuyendo imperativamente la maternidad a la gestante, frustrando de esta manera de antemano todo intento de consumar esa técnica.

Es decir, el criterio que parece subyacer en las normas proyectadas es que la fecundación asistida heteróloga con semen de donante es lícita; mientras que no lo es la maternidad por subrogación. La primera se respalda (y de hecho se la incentiva); la segunda resulta excluida. Comprobamos así que el criterio sobre la legitimidad éticojurídica de los procedimientos es insoslayable a la hora de regular sus efectos filiativos.

Finalmente, resta constatar que hay una cierta incongruencia en hacer primar en un caso "la voluntad procreacional" (consentimiento del marido) y en el otro el elemento biológico (la gestación). Si es la voluntad del marido la que permite la atribución de paternidad, ¿por qué no sucede lo mismo con la mujer que encarga la gestación de un niño a otra y que tambien ha expresado su voluntad de ser madre del hijo que nace?

\section{VI. ¿Hacia una "contractualización" de la filiación?}

La tendencia que se aprecia en el contexto general de legalizar las técnicas de reproducción asistida en las que intervienen terceros y se produce la inevitable disociación de los lazos filiativos, puede estar dando pie a una configuración diversa del entero Derecho de la filiación, si no de la misma imagen pública de la familia.

En efecto, el favorecimiento de las técnicas heterólogas y, en algunos ámbitos, de la maternidad por subrogación, implica el quiebre del sistema filiativo tradicional, 
que amenaza ser sustituido por otro que ve en los lazos entre padre, madre e hijo, no la fuerza del amor incondicionado, sino sólo la de una voluntad negocial.

Al poner el acento en la voluntad procreativa, en los instrumentos en los que se otorga el consentimiento para la fecundación con semen ajeno u óvulos ajenos, en el Surrogacy Parent Agreement, es evidente que estamos cruzando la frontera que separa el campo de los asuntos de familia, indisponibles y de orden público, al sector del mercado y la libre contratación.

Con la regulación de los supuestos de filiación de los nuevos procesos biorreproductivos no estamos solamente complementando nuestro Derecho con una nueva figura de filiación formal, que debe sumarse a la filiación adoptiva y a la filiación por naturaleza. Más bien estamos introduciendo un germen de destrucción de la clásica visión del hijo como un don del amor, que no se produce ni se controla, sino que se acepta y se recibe como es. La introducción del elemento "voluntad procreacional" o "voluntad de acogida" no puede tener un significado limitado a los casos de reproducción asistida y casi por la fuerza misma de las cosas puede expandirse a todos los casos de filiación. La filiación ya no vendrá determinada por la naturaleza, sino por el contrato. No estaremos frente a una cuestión de status, sino de contractus.

Ni siquiera estaremos regresando al formalismo napoléonico ya que las reglas de posesión de estado o del reconocimiento voluntario se basaban en presunciones de la relación biológica. Aquí, en cambio, se pretende establecer una filiación que va más allá de la ficción legal y que se revela como de origen contractual. Así lo expresa un autor francés comentando la ley de 1994: "Aceptando tratar aparte la filiación del hijo concebido por una asistencia médica a la procreación el legislador de 1994 tenía que resolver una triple dificultad. No le era posible hacer descansar el establecimiento de la filiación sobre la verdad biológica, al menos para uno de los vínculos parentales, incluso para los dos si se admite que él pretendía tratar igualmente la donación de embriones. Le era difícil hacer jugar a la posesión de estado su rol supletorio habitual en la medida que él quería establecer rápidamente un lazo de filiación ab initio ni su rol confirmativo puesto que no era cuestión de confirmar una verdad biológica sólo presumida. Le quedaba por tanto decidir arbitrariamente una filiación abiertamente ficticia usando el poder de ficción de la ley lo que no era nuevo en el derecho de filiación si se piensa por ejemplo en la adopción plena. Pues bien, él no ha elegido esta vía prefiriendo insistir sobre la convención otorgada por los potenciales padres y su ejecución puntual, creando así una filiación convencional del todo nueva" ${ }^{23}$.

Para la profesona norteamericana Janet L., Dolgin, esta filiación convencional que se propone subvertir la visión clásica de la paternidad y la maternidad es un signo más de una más amplia revisión de la concepción del fenómeno familiar. En sus palabras: "El permitir que la familia sea definida a través de la elección [choice] - y a través

23 HAUSER, Jean, "Filiation. Identification génétique. Procreation médicalement assistée", en Editions du JurisClasseur, 2, 1997, arts. 311-19 y 311-20, pp. 12 y ss. 
de la intención - puede ser la transición hacia la familia definida a través del contrato. Un aspecto esencial de la ideología tradicional de la familia es la inexorabilidad de las relaciones familiares. Las relaciones familiares, entendidas como algo basado en la sangre o los genes, sólo reflejan la inevitabilidad de los procesos naturales... Sin embargo, en casos tales como Davis y Johnson la familia no se distingue del mercado. Más bien, la voluntad (a menudo puesta en evidencia por referencia a contratos actuales) como base sobre la cual se construyen las relaciones familiares, sustituye a la sangre y los genes en la constitución de las relaciones paterno-filiales. En esta construcción, elección [choice] y negocio [bargain], elementos esenciales de la interacción contratual, pasan a ser centrales para la definición de la familia" ${ }^{24}$.

\section{El valor de la dignidad humana y el interés superior del hijo: claves superadoras}

El valor de la dignidad humana incluye también y en forma especial el proceso de generación de una nueva persona. La tecnología no puede justificarse por sí misma y por la realización de fines ajenos a quienes son objeto de ella. La tecnología reproductiva debe examinarse a la luz de criterios de justicia. Sólo son justas aquellas intervenciones que no instrumentalizan el acto de unión personal de los cónyuges ni el ser humano que puede resultar de ellas. Todo ser humano tiene derecho a ser engendrado de una manera digna. De lo contrario, nos estaremos acercando cada vez más al "Mundo feliz" de Aldous Huxley o al del universo cibernético y virtual de la película The Matrix de los directores Larry y Andy Wachowski (1999), donde se anuncia que en el futuro los seres humanos en realidad no nacen, sino que son cultivados...

El interés superior del niño, si se quiere reconocerlo en toda su potencialidad, debe incluir el interés en no ser tratado como material de reproducción, de venir al mundo por el amor incondicionado de hombre y mujer que se unen establemente para fundar un hogar donde puede ser acogido, criado y educado. Como sostiene Spaemman, "pertenece a la forma temporal de la persona humana que su comienzo no esté en las manos de una producción intencional, sino que acontezca con motivo de un acto humano que no tiene en absoluto como fin inmediato la elaboración de un 'producto'.

24 DOLGIN, Janet L., Defining de family. Law, Technology, and Reproduction in an Uneasy Age, New York University Press, New York-London, 1997, p. 208-209. Más adelante agrega: "La maternidad subrogada y la nuevas tecnologías reproductivas rompen las concepciones tradicionales de las familia en dos diferentes, pero igualmente basicos, aspectos. Primero, estos fenómenos desafían la noción largamente asentada de que el lazo entre padre e hijo debe ser fundado en amor, no en dinero. En muchos estados de los Estados Unidos, las leyes de adopción prohíben el intercambio de dinero por un niño. Sin embargo, los acuerdos comerciales de subrogación y el creciente mercado de los tratamientos de infertilidad envuelve el intercambio de dinero por gametos, embriones y niños, siguiendo una variedad de acuerdos contractuales. Segundo, las nuevas tecnologías reproductivas, incluyendo la subrogación gestacional.... desordena las suposiciones acerca de los correlatos sociales de la reproducción biológica. Especificamente, estos fenómenos rompen las suposiciones básicas que rodeaban las comprensiones públicas de la relación padre-hijo. Ciertamente, la gente puede elegir crear familias a través de la tecnología reproductiva o la subrogación que, una vez formadas, parecen familias tradicionales en que sus miembros se miran uno al otro como profunda y definitivamente ligados. Pero como ellas se han fundado en la elección, más que creadas como una consecuencia inevitable de un proceso natural, tales familias pueden siempre ser reemplazadas por otras, atribuibles a otras y diferentes elecciones" (p. 250) 
Sólo así entra el hombre en la vida y hace valer su propio derecho 'por naturaleza' como creación de Dios o de la naturaleza, pero no de sus padres. Genitum non factum, engendrado y no amasado a mano en una probeta y, de este modo, sin derecho a pedir cuentas por su existencia" 25 .

De esta forma, todas las técnicas que disocian la unión corporal de la procreación no debieran ser fomentadas por la ley civil. Aquellas que transgreden seriamente el interés superior del niño haciendo intervenir a terceros como donantes de gametos o prestadores de servicios de gestación, debieran excluirse expresamente, mediante normas que las prohíban o al menos que las desalienten.

La regulación de la filiación debiera tener en cuenta también este interés superior, de manera que si de hecho se producen técnicas disociativas de los vínculos parentales, la solución debiera centrarse en el bienestar y en la protección del menor concebido.

Pensamos que una armonización de los criterios biológicos, que deben permanecer como los fundantes de las relaciones filiativas, con normas provistas por los sistemas de adopción y del cuidado personal de los hijos pueden considerarse para solucionar los casos de procreaciones realizadas en contra de los intereses del niño ${ }^{26}$.

Así, en caso de fecundaciones heterólogas, el niño tendrá como padre por naturaleza el donante de espermios, pero se estimará adoptado legalmente en virtud de la voluntad del varón que consiente en la práctica de esta técnica. Esta adopción debiera ser simple, y producir sólo las obligaciones paternas y no los derechos, salvo que el juez conceda algunos (como la tuición) cuando estime que en el caso concreto ello se justifica en virtud del interés del niño.

El niño en todo caso debe tener derecho a conocer la identidad del progenitor biológico, y no ha podido constituirse la adopción del varón consintiente, podrá hacer valer, si no la paternidad completa, al menos una acción de responsabilidad que incluya una pensión alimenticia, en contra del que a sabiendas de su destino cedió los gametos.

En los casos de maternidad por subrogación, si la madre gestante es también la genética, debe atribuirse a ella la maternidad. Ha de prohibirse la posterior adopción del hijo por parte de la pareja que contrató con ella los servicios de gestación. El cuidado personal del niño lo determinará el juez atendiendo nuevamente al interés y bienestar del niño.

25

SPAEMANN, Robert, "Sobre el concepto de dignidad humana", en Lo natural y lo racional. Ensayos de antropologia, Rialp, Madrid, 1989, pp. 116 y 117.

26 SANCHO REBULLIDA, F., "Los estudios previos y las líneas previsibles de la futura regulación española" en I/ Congreso Mundial Vasco La filiación a finales del siglo XX, Madrid, 1988, p. 110, señala que "Supuesto el derecho del hijo a conocer la identidad de sus progenitores, le resta al Derecho establecer el contenido de esa determinación y sus relaciones con los supuestos de adopción con determinación de la filiación por naturaleza" 
Si la madre sustituta no es la genética, el problema debiera resolverse de un modo similar a las técnicas heterólogas. La madre genética será madre por naturaleza, pero la gestante se considerará de pleno derecho madre adoptiva del hijo, con todas las obligaciones de la maternidad, y con los derechos que el juez le asigne. El cuidado personal del hijo será también determinado por el juez.

En las técnicas postmortem, el niño concebido, aún después de la muerte del titular de los gametos, será considerado hijo por naturaleza de éste, con independencia de su voluntad, pero no participará en su sucesión, por no haber existido al momento de la apertura.

Tratándose de embriones criopreservados, deben estos ser tratados como seres humanos y facilitar su nacimiento, en lo posible por medio de su implantación en la mujer cuyos óvulos permitieron su concepción. De no ser ello factible, el camino a elegir es dudoso. La autorización de su gestación por parte de una pareja adoptante puede servir para evitar su destrucción, pero deberá cuidarse que con ello no se favorezca o incentive la creación de más embriones para ser objeto de intercambio o donación ${ }^{27}$.

Como podemos ver, se trata de problemas dificilísimos, y que probablemente no serán los únicos que se nos presenten si seguimos olvidando que por sobre el querer humano está el mismo ser humano.

Como señala C. S. Lewis el poder de la tecnología que pretende superar la dignidad humana promete un poder engañoso al hombre: "Es la ganga que nos ofrece el mago: entrega tu alma, recibe poder a cambio. Pero una vez que hayamos entregado nuestras almas, es decir, que entregamos nuestras personas, el poder que se nos otorga no nos pertenecerá... si el hombre elige tratarse a sí mismo como materia prima, se convertirá en materia prima; no en materia prima a manipular por sí mismo, como con condescendencia imagina, sino a manipular por la simple apetencia, es decir, por la mera Naturaleza, personalizada en sus deshumanizados manipuladores" 28 .

27 El Papa Juan Pablo II, en un discurso del 24 de mayo de 1996, llamó a detener la producción de embriones humanos para criopreservación "teniendo en cuenta que no se vislumbra una salida moralmente lícita para el destino humano de los miles y miles embriones 'congelados' que son y siguen siendo siempre titulares de los derechos esenciales y que, por tanto, hay que tutelar juridicamente como personas humanas" ( $L$ 'Osservatore romano, 31 de mayo de 1996, pp. 17-18). Las dudas que presenta la solución de la adopción prenatal que algunos propician como solución de ultima ratio para los embriones congelados tiene dificultades que provienen de la lógica de producción en la que se inserta. Cfr. FAGGIONI, MAURIzIO, "La cuestión de los embriones congelados" en L'Osservatore romano 30 de agosto de 1996, pp. 9-11.

${ }^{28}$ C. S. LEWIS, La abolición del hombre, Encuentro ediciones, Madrid, 1990, pp. 71-72 